\title{
ОЦЕНКА УСЛОВИЙ ПОДРАБОТКИ ГЕОЛОГИЧЕСКОЙ СКВАЖИНЫ НА СОСТОЯНИЕ ВОДОЗАЩИТНОЙ ТОЛЩИ
}

\author{
А.Ю. Шумихина \\ Горный институт УрО РАН, г. Пермь
}

\begin{abstract}
Аннотация: В работе приводится геомеханическая оценка потенциальной опасности нарушения герметичности затампонированной скважины. Математическое моделирование проводилось в двухмерной постановке методом конечных элементов и отражало установленные по геофизическим исследованиям особенности ее геологического строения. Связь между деформациями и напряжениями на допредельной стадии описывалась законом Гука, а предельные напряжения в области сжатия определялись критерием Кулона-Мора. Анализ нарушения сплошности слоев ВЗТ в области действия растягивающих напряжений основывался на их превышении предела прочности соляных пород при растяжении. Для оценки потенциальной опасности нарушения герметичности затампонированной скважины выполнялся анализ распределения субвертикальных касательных напряжений в породном массиве. В качестве прочностных характеристик использовалась прочность сцепления на сдвиг цементного камня с каменной солью.

Ключевые слова: математическое моделирование, метод конечных элементов, геологическая скважина, нарушение герметичности, сцепление цементного камня с солями, критерий прочности, упругопластические деформации, соляные породы.
\end{abstract}

Как показывает горная практика, геологоразведочные скважины могут являться каналами проникновения воды и рассолов в выработанное пространство калийных рудников. Поэтому нормативные документы предписывают создание охранных целиков вокруг геологических скважин. Вместе с тем иногда возникают ситуации, когда по тем или причинам предохранительный целик вокруг скважины не оставлен. В этом случае данный участок относится к потенциально опасным и требует оценки соблюдения безопасных условий подработки водозащитной толщи (В3Т).

В данной работе проведена геомеханическая оценка потенциальной опасности нарушения герметичности затампонированной скважины, расположенной вблизи границы шахтного поля калийного рудника. На данном участке два сильвинитовых пласта - АБ и КрII. Оценка и прогноз состояния ВЗТ в районе скважины проводились по широтному разрезу.

Математическое моделирование, направленное на оценку безопасных условий подработки ВЗТ в окрестности геологической скважины, проводилось в упругопластической постановке для условий плоского деформированного состояния (ПДС) методом конечных элементов и отражало установленные по геофизическим исследованиям особенности ее геологического строения. Рассматривалась идеальная упругопластическая среда, для которой связь между деформациями и напряжениями на допредельной стадии описывается законом Гука, а предельные напряжения в области сжатия определяются параболической огибающей кругов Мора [1]:

$$
\tau_{n p}=\sqrt{\left(\sigma_{p}+\sigma_{n}\right)\left[2 \cdot \sigma_{p}-2 \sqrt{\sigma_{p}\left(\sigma_{p}+\sigma_{c \varkappa}\right)}+\sigma_{с ж}\right]}
$$

где $\sigma_{c ж}$ и $\sigma_{p}$ - пределы прочности на сжатие и растяжение, $\sigma_{n}-$ нормальное напряжение в плоскости действия максимального касательного напряжения $\tau_{\max }$.

Напряжения $\tau_{\max }$ и $\sigma_{n}$ вычисляются через значения главных напряжений:

$$
\tau_{\text {max }}=\left(\sigma_{1}-\sigma_{3}\right) / 2 \quad \sigma_{n}=\left(\sigma_{1}+\sigma_{3}\right) / 2
$$

где $\sigma_{1}$ и $\sigma_{3}$ - максимальные и минимальные главные напряжения. Для условий ПДС главные напряжения определяются по формулам: 


$$
\sigma_{1}, \sigma_{3}=\frac{1}{2}\left[\left(\sigma_{x}+\sigma_{y}\right) \pm \sqrt{\left(\sigma_{x}-\sigma_{y}\right)^{2}+4 \tau_{x y}^{2}}\right]
$$

В области растяжения предельное напряжение ограничивалось пределом прочности на растяжение:

$$
\sigma_{1}=\sigma_{p a c m}
$$

Для описания развития во времени деформационных процессов в подработанном массиве использовался реологический подход, основанный на модификации известного метода переменных модулей [2].

На рис. 1. приведены расчетные оседания земной поверхности вдоль геомеханического профиля на настоящий момент времени (2019 год) и на момент завершения процесса сдвижения. Как видно из рисунка, наибольший градиент оседаний приурочен к району скважины.

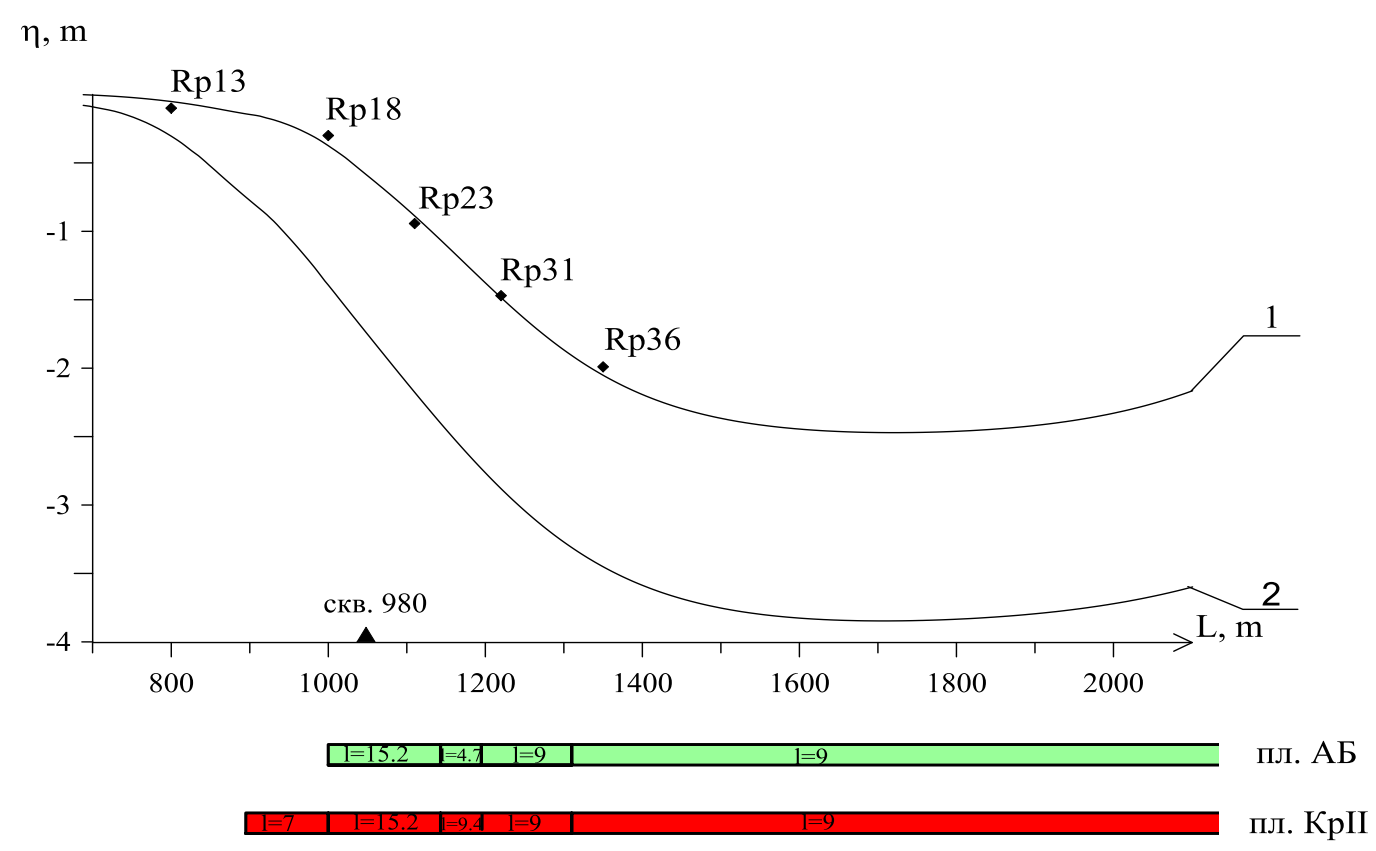

\footnotetext{
$l=9$ - участки выработанного пространства с различными параметрами (1 - межосевое расстояние)

Rp31 - номер репера маркшейдерской линии №5
}

Рис. 1. Расчетные оседания земной поверхности: 1 - на 2019 г; 2 - на конец процесса сдвижения

Результаты геомеханической оценки техногенного нарушения сплошности ВЗТ на на 2019 год и на конец процесса сдвижения представлены на рис. 2. Здесь одновременно иллюстрируется формирование в ВЗТ зон трещиноватости за счет сдвига и растяжения. По мере развития процесса сдвижения в районе скважины формирование зон техногенной трещиноватости не прогнозируется.

Для оценки потенциальной опасности нарушения герметичности затампонированной скважины выполнялся анализ распределения субвертикальных касательных напряжений в породном массиве. На рис. 3 показано изменение касательных напряжений вдоль ствола скважины. Как видно, максимальные касательные напряжения в интервале соляной толщи не превышают 0,8 МПа. Средняя величина сцепления цементного камня с солями по данным [3] составляет 2 МПа, что свидетельствует об обеспечении сохранности герметичности скважины. 


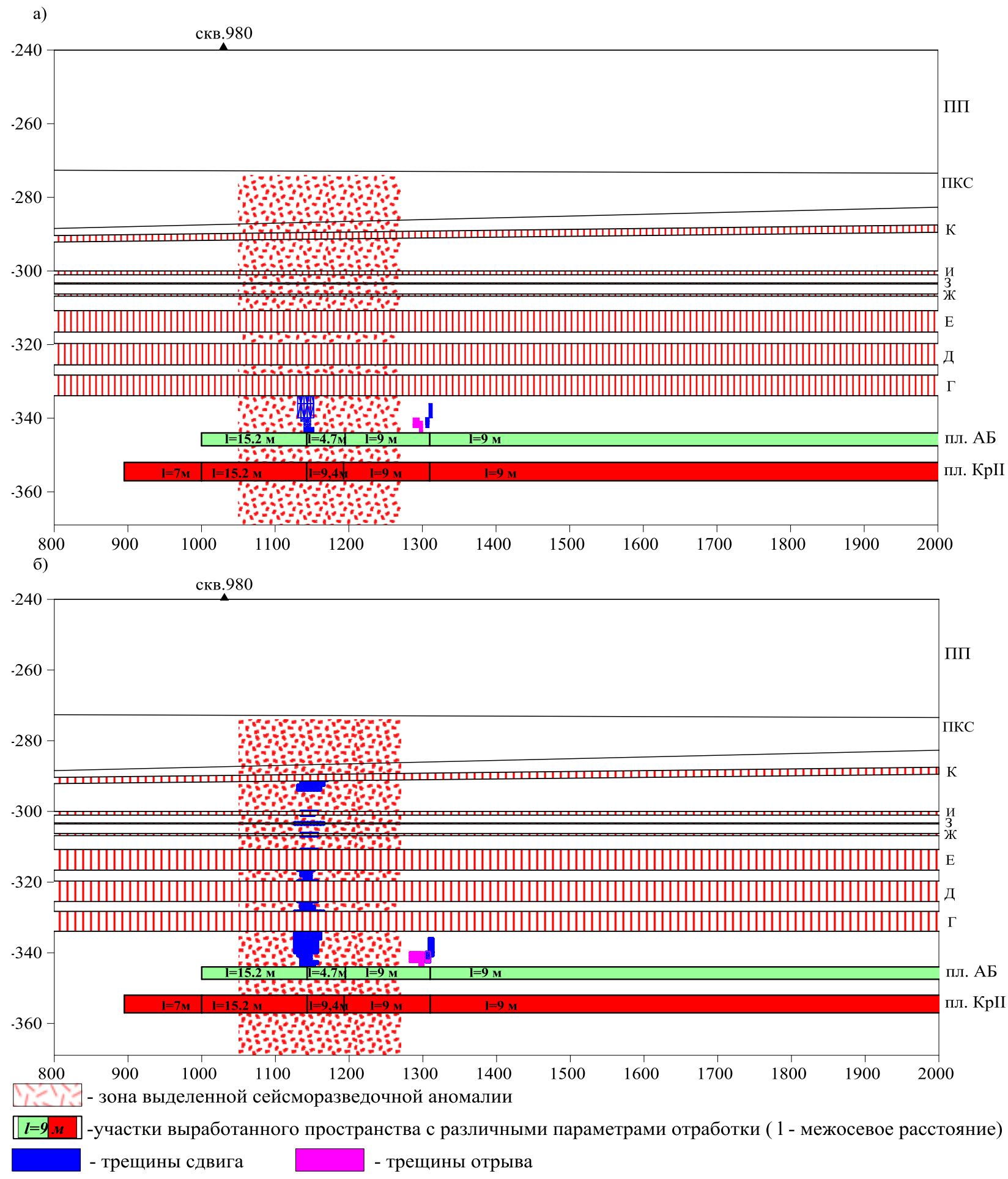

Рис. 2. Характер техногенного нарушения сплошности ВЗТ на: а) 2019 г; б) на конец процесса сдвижения

Количественная оценка условий разрушения соляных пород вследствие сдвига производилась по критерию Кулона, представленному в безразмерном виде:

$$
R=\frac{\tau_{\max }}{\tau_{n p}} \geq 1
$$

Напряжение $\tau_{\max }$ определялось выражением (2).

$$
\tau_{n p}=C+\sigma_{n} \operatorname{tg} \varphi
$$


где $C$ - коэффициент сцепления, $\varphi$ - угол внутреннего трения, $\sigma$ - нормальное напряжение в плоскости действия $\tau_{\max }$ определяется выражением (2).

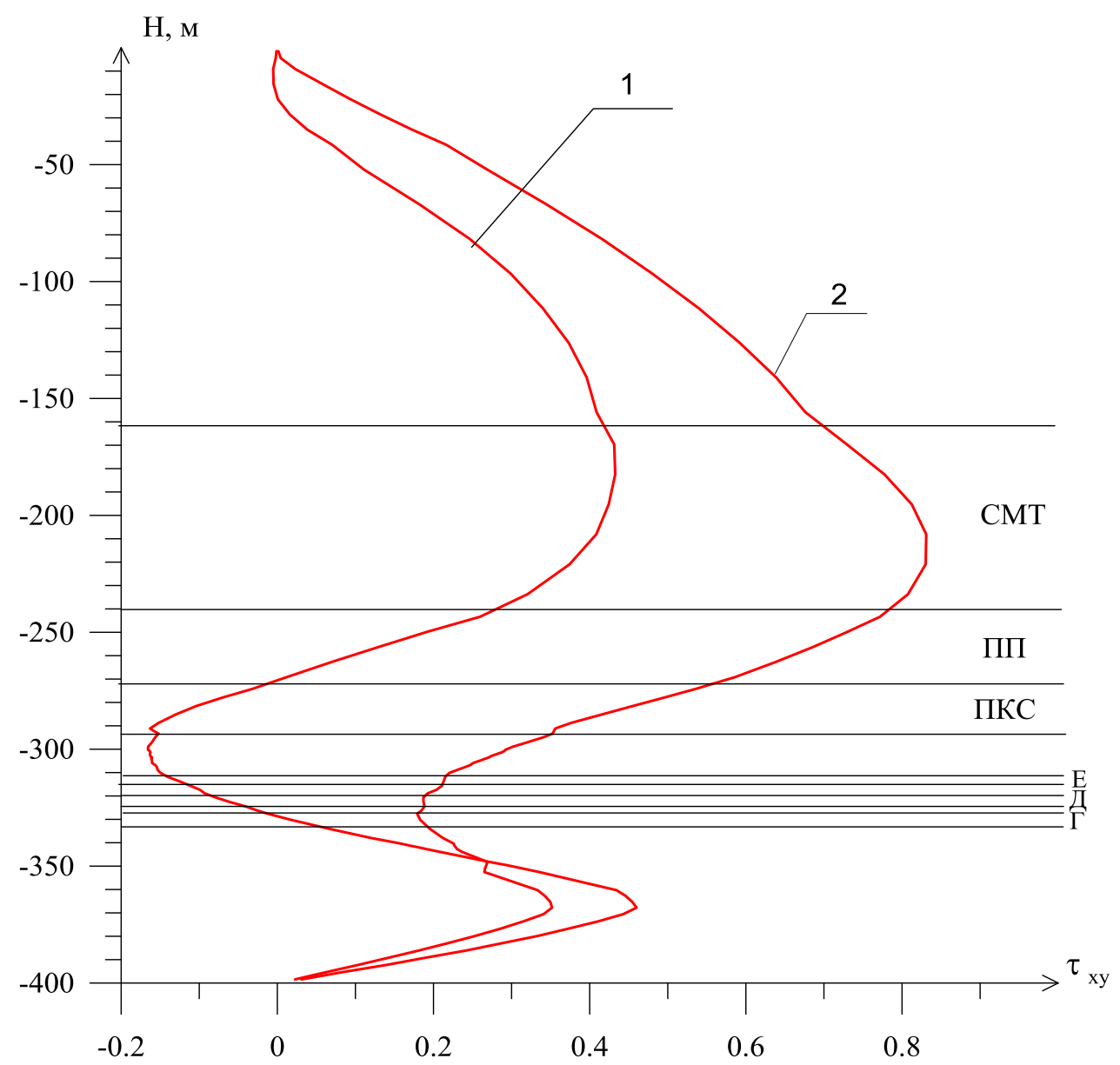

Рис. 3. Распределение сдвиговых напряжений по разрезу вдоль скважины: 1 - на 2019 г; 2 - на конец процесса сдвижения

В качестве прочностных характеристик (прочность сцепления на сдвиг цементного камня с каменной солью) соляных пород использовались средние величины, рекомендованные в работах $[3,4]$. Считалось, что опасность развития зон техногенной трещиноватости отсутствует при величине безразмерного параметра $\mathrm{R}<1$.

Результаты критериальных оценок состояния ВЗТ показали, что вдоль скважины зон, где величина параметра R приближается к 1, не выделяется. Таким образом, геомеханическая оценка состояния ВЗТ показала, что на данном этапе в пределах геологической скважины безопасные условия подработки обеспечиваются вплоть до завершения процесса сдвижения.

\section{БИБЛИОГРАФИЧЕСКИЙ СПИСОК}

1. Кузнецов Г.Н. Механические свойства горных пород. - М.: Углетехиздат. - 1947. - 180 с.

2. Барях А.А., Самоделкина Н.А. Об одном подходе к реологическому анализу геомеханических процессов // Физико-технические проблемы разработки полезных ископаемых. - 2005. - №6. - С. 32-41.

3. Толкачев Г.М., Шилов А.М., Козлов А.С., Болотов В.П. Расширяющийся тампонажный материал для крепления кондукторов в скважинах на территории ВКМКС // Вестн. ПГТУ: Нефть и газ. - 2000. - Т. 2, № 4. - С. 80-83.

4. Толкачев Г.М, Козлов А.С. Технологии и опыт строительства скважин для решения задач комплексного освоения калийных и нефтяных месторождений // Горное оборудование и электромеханика. 2011. - № 12. - С. 29-32. 